\title{
Uma revisão sistemática sobre a relação entre a presença de vegetação e o desempenho acadêmico
}

\author{
A systematic review about the relationship between presence of \\ vegetation and students' performance
}

\section{Una revision sistemática de la relación entre la presencia de vegetación y el rendimiento académico}

Recebido em 23/02/2021. Aceito em 03/04/2021.

COSTA, Gabriela Teixeira da ${ }^{1}$

CALIXTER, Abner Luis ${ }^{2}$

\begin{abstract}
1Universidade de Brasília, Faculdade de Arquitetura e Urbanismo, Reabilita. Brasília, Distrito Federal, Brasil. gabrielateixeiradacosta@gmail.com ORCID: 0000-0003-2048-9782
\end{abstract}

2Universidade de Brasília, Faculdade de Arquitetura e Urbanismo, Reabilita. Brasília, Distrito Federal, Brasil. calixter@brandeis.edu ORCID: 0000-0002-6408-9708 


\title{
Resumo
}

A disparidade entre resultados de alunos de escolas públicas e particulares é facilmente notada nas avaliações de ingresso ao ensino superior. Diversos estudos relacionam a influência do espaço físico sobre a capacidade de concentração e aprendizagem. Por sua vez, a Teoria de Restauração da Atenção aponta ganhos no desempenho com o uso de intervalos entre atividades. Esse efeito pode ser potencializado pela presença de vegetação. Fator que pode orientar novas medidas a respeito do posicionamento físico da unidade escolar e seus componentes essenciais. Foi realizada uma revisão sistemática da literatura, baseada no sistema Prisma, selecionando 18 artigos com o objetivo de identificar qual é o vínculo entre a vegetação e o desempenho acadêmico. Esses artigos descrevem tipo de vegetação, sua posição e o momento de contato com ela, relacionando esses fatores com o desempenho. Foram encontradas correlações positivas com vegetações localizadas em buffers de até $4,8 \mathrm{~km}$, em contatos do tipo passivo e ativo. A faixa etária parece interferir diretamente na dimensão do buffer efetivo. Os resultados mostram conclusões variadas a respeito do impacto do espaço verde na performance acadêmica. Há um número limitado de publicações, com metodologias diversas. As recomendações para pesquisas futuras incluem testar a influência da presença de vegetação em novos contextos climáticos e socioculturais.

Palavras-Chave: Desempenho escolar; vegetação; estresse; atenção.

\begin{abstract}
The disparity between students grades from public and private schools are easily noticed at the admission tests for college. Several studies relate the influence of physical space to the ability of concentrating and learning. The Attention Restoration Theory points out towards gains on performance having breaks between activities. The effect of these breaks can be enhanced by the presence of vegetation. This aspect can guide new measures regarding the location of the school and its essential components. For the systematic literature review, based at Prisma methodology, 18 articles were selected in order to identify the relationship between vegetation and students' performance. The articles describe the type of vegetation, its position and the moment of contact with it, relating these points to the performance. Significant positive correlations were found with vegetation of various sizes, located in buffers of up to $4.8 \mathrm{~km}$, in passive and active group interactions. Group's age directly interferes with the size of the effective buffer. The results show diverse conclusions regarding the impact of green space on academic performance. There are a limited number of publications, with different methodologies. Recommendations for future researches include gathering aspects of influence of vegetation at new climatic and cultural contexts.
\end{abstract}

Key-Words: Student performance; vegetation; greenness; stress; attention. 


\section{Introdução}

O desempenho escolar possui grande correlação com o futuro sucesso no ensino superior e no mercado de trabalho (LI et al., 2019). O interesse no impacto que o meio tem sobre o desenvolvimento do indivíduo e suas conquistas acadêmicas não é recente.

Como exemplo, a influência do contexto familiar no desenvolvimento do aluno já era estudada na década de 1950. Os dados levantados incluíam renda, ocupação e escolaridade dos pais, além de informações morfológicas como número de filhos e a ordem de nascimento desses. Na década de 1970 esse interesse foi transferido para a cultura que é repassada pela família. Enquanto isso, nos anos 1980 , a atenção se volta para a dinâmica de socialização e o posicionamento dos pais em relação a vida escolar (ALVES et al., 2013).

Segundo o Relatório Pedagógico do Enem 2011-2012 (INEP, 2015), o desempenho médio dos alunos de escola particular superou o da escola pública em mais de 100 pontos nas provas de redação e matemática. Quando observado o gráfico de distribuição de renda, a discrepância é ainda maior. A diferença da nota média dos estudantes com renda familiar acima de 20 salários mínimos em relação aos de renda familiar de até 1 salário mínimo excedeu a marca dos 200 pontos na prova de matemática.

Visto que há uma grande variação de performance escolar associada a renda (KUO et al., 2018) sobrepujando quesitos como sexo e etnia (INEP, 2015) - é relevante procurar alternativas de custo reduzido que auxiliem no aprimoramento do potencial de aprendizagem dos alunos de escolas públicas (BROWNING e RIGOLON, 2019).

Muito já é discutido sobre a repercussão que fatores atrelados ao espaço físico tem no desenvolvimento infantil - entre eles barulho, dimensões da escola, iluminação e climatização. No entanto, há quesitos ainda pouco explorados como a presença de vegetação, que pode ter impacto equivalente ao da estrutura física da escola (MATSUOKA, 2010).

A curiosidade pela interação da paisagem no campus escolar e sua vizinhança, com o desempenho acadêmico, vem crescendo desde o destaque da Teoria de Restauração da Atenção (ART) (KAPLAN, 1995). Teoria que busca compreender a forma como um intervalo entre atividades auxilia na recuperação da capacidade de realizá-las de modo eficaz.

Essa perspectiva traz visibilidade para a influência que fatores de escala urbana - como presença de parques e trajetos caminháveis da residência até a escola - podem ter na qualidade de vida e no processo de aprendizagem. A abordagem de incentivo para a relação com o verde pode ser uma didática de implementação relativamente simples e de baixo custo, quando incluída no planejamento desde o princípio.

Assim, essa revisão se justifica pela constatação da necessidade de agrupar os dados das pesquisas já existentes a respeito dessa temática relativamente nova, levantando os pontos de coesão e de discordância entre os autores. Facilitando, dessa forma, a identificação de fatores que causaram variação nos resultados e apontando novas linhas de estudo necessárias para complementar a compreensão do tema.

De modo mais claro, o objetivo deste estudo é identificar qual é o vínculo entre a presença de vegetação e o desempenho acadêmico. Através de uma revisão dos artigos, pretende-se caracterizar as principais variáveis para que esse vínculo ocorra, bem como abordagens relevantes para pesquisas posteriores.

\section{Revisão bibliográfica}

Na etapa de revisão bibliográfica serão expostos alguns dos parâmetros mais abordados pelos pesquisadores na tentativa de esclarecer como a presença de vegetação pode influenciar o meio. 
Estes parâmetros foram divididos em restauração de concentração, redução de estresse, momento de contato com o verde, posicionamento da vegetação, quantidade e tipo de vegetação, interações entre alunos e diferença real de desempenho.

O processo visa traçar uma evolução na abordagem das pesquisas e identificar seus conflitos. Essa etapa auxiliará na revisão sistemática através da percepção dos pontos mais significativos a se analisar no tema.

As informações a respeito da relação entre vegetação e desempenho foram categorizadas na tentativa de identificar como, quando e o quanto essa abordagem pode ser efetiva.

\subsection{Restauração de concentração}

Concentração endógena ou ativa se refere à capacidade de um indivíduo de manter o foco em algo de forma intencional (JOHNSON et al., 2019). A Teoria da Restauração da Atenção (ART) estuda os efeitos da fadiga sobre essa capacidade e como ela pode ser restaurada com pausas para descanso (KAPLAN, 1995).

A exposição de um indivíduo a ambientes naturais apresenta uma influência restaurativa sobre o estresse e a fadiga mental. Na década de 90 buscava-se entender se esse tipo de interação poderia recuperar de forma mais rápida a capacidade de um indivíduo de desenvolver atividades que geram fadiga mental, quando comparada a um intervalo comum. Por consequência, essa exposição poderia melhorar o desempenho desse indivíduo (KAPLAN, 1995). Era o início do refinamento da ART.

Os principais fatores avaliados quando se trata de Restauração da Atenção são a fadiga de concentração e o estresse gerados por uma atividade. Há uma significativa diferença na influência entre o impacto da capacidade de concentração e do estresse no desempenho de atividades que requerem concentração ativa (KAPLAN, 1995). A recuperação de ambos pode funcionar de modo independente, bem como a sua influência sobre a performance de um indivíduo (JOHNSON, 2019).

A ART é relevante tanto para o desempenho acadêmico quanto para atividades de trabalho. Em ambiente escolar pode ser vista a relação entre a exposição dos alunos à natureza e a recuperação mais eficiente dos recursos cognitivos responsáveis pela autorregulação emocional e pelo funcionamento executivo - ou concentração endógena (LI et al., 2019).

No entanto, quando um tempo de descanso em ambiente natural inclui o uso de eletrônicos, podem ser perdidos tanto o efeito maximizado pela presença de vegetação quanto o do próprio momento de intervalo (JIANG; SCHMILLEN; SULLIVAN, 2019).

\subsection{Redução de estresse}

O estresse é o modo de reação de um indivíduo a situações de ameaça ao bem-estar. Essa resposta se apresenta de forma psicológica, física e, por vezes, comportamental (BAUM et al., 1985, apud ULRICH et al., 1991). Visto que o estresse por fadiga pode levar a declínios cognitivos, a reabilitação do indivíduo nesse estado, por consequência, leva à regeneração da capacidade cognitiva (ULRICH et al., 1991).

A avaliação de fatores psicológicos - como autoavaliação de estado afetivo - e fisiológicos - como ritmo cardíaco, tempo de trânsito de pulso, tensão muscular e condutância da pele - são necessários para a compreensão de como se desenvolve o processo do estresse (ULRICH et al., 1991).

O contato com ambientes naturais, por exemplo, demonstrou superar a vivência do ambiente urbano em ambos os aspectos - psicológicos e fisiológicos - na capacidade de apaziguar os efeitos do estresse após voluntários assistirem um filme sobre prevenção de acidentes. Trazendo uma recuperação mais rápida e completa.

É necessário ressaltar que o conceito de restauração pode se aplicar não apenas a situações de excitação psicológica, como também a estados de sub estimulação (ULRICH et al., 1991). 
Em outro experimento, um teste de exposição passiva utilizou óculos 3D para simular o passeio por ambientes com e sem cobertura de árvores, com finalidade de aplicar testes de redução de estresse. Os participantes que foram delegados ao vídeo de uma vizinhança com $62 \%$ de área coberta por copas de árvore tiveram cerca de $60 \%$ a mais de resultado na recuperação de estresse quando comparados aos participantes que assistiram ao vídeo de outro ambiente com apenas $2 \%$ de cobertura (JIANG et al., 2016). Apesar de a simulação virtual não ser considerada um dos testes mais efetivos, foi possível observar uma alta relação entre a recuperação dos participantes com o tipo de ambiente ao qual foram expostos.

Resultados de interferência positiva também foram obtidos em experiência com alunos observando paisagens naturais - através de uma janela - em intervalo entre avaliações (LI e SULLIVAN, 2016).

\subsection{Momento de contato com o verde}

Para a obtenção de melhora de desempenho em uma atividade, a presença de verde por si não é universalmente eficaz. É essencial observar o momento em que ocorre o contato.

A exposição ao ambiente natural não tem os melhores efeitos no momento de realização das atividades de concentração, mas sim no de recuperação entre essas (LI e SULLIVAN, 2016). Fato que reafirma a ideia da Teoria de Restauração da Atenção sobre o impacto dos intervalos entre atividades para restauro de concentração e redução de estresse (KAPLAN, 1995).

Passar o horário de almoço em ambiente natural, por exemplo, pode ter efeito positivo na autoavaliação de bem-estar (WALLNER et al., 2018). Quanto à concentração, instrutores relatam gastar apenas metade do tempo chamando a atenção dos alunos de volta para uma tarefa após uma aula na natureza (KUO et al., 2018).

Um intervalo de 30 minutos para realização de caminhada em ambiente natural, antes da realização de uma tarefa que exija concentração endógena, também melhora o desempenho (JOHNSON et al., 2019). Enquanto o mesmo período de caminhada em ambiente urbano reduz esse desempenho, possivelmente devido à fadiga causada pelo excesso de informações presentes no roteiro.

É recomendada a implantação de áreas verdes nas rotas de acesso às escolas e no próprio terreno dessa, com fim de melhorar a capacidade de atenção, o humor e a concentração (NORWOOD et al., 2019).

\subsection{Posicionamento da vegetação para maior influência positiva}

O tipo de interação e o posicionamento da vegetação são fortes determinantes de seus efeitos. A exposição passiva à natureza, a exemplo, tem sido prescrita como forma de tratamento médico para efeitos comportamentais, cognitivos e emocionais. Há indícios de que o contato com esse tipo de ambiente possa vir a ser um tratamento para Transtorno do déficit de atenção com hiperatividade.

Isso parte do pressuposto de que a presença de espaços naturais pode melhorar a capacidade de autocontrole. Estudos médicos acreditam nos benefícios de curto prazo da exposição a esses espaços, enquanto os dados para resultados de longo prazo ainda são inconclusivos (Norwood et al., 2019).

A relação entre arborização e desempenho escolar é mais significativa para crianças jovens quando considerado como base o terreno da escola e um buffer de $25 \mathrm{~m}$ ao seu redor. Gramados, na maioria das pesquisas, foram considerados como não correlacionados à performance acadêmica (KUO et al., 2018). No entanto, ainda analisando estudantes de ensino fundamental, é possível encontrar resultados positivos com buffers entre 1 e $2 \mathrm{~km}$ (WU, 2014)

Já quando se trata de pontuação em testes admissionais para faculdade, é possível encontrar uma relação de ganho positivo na pontuação analisando a densidade de vegetação em buffers de até 4,8 $\mathrm{km}$. Diferença que pode ser interpretada como uma possível distinção entre a relação de crianças e adolescentes com a escala urbana. Observa-se que há diferenças nos parâmetros de mobilidade 
urbana e padrões de atividade física, condicionados à independência em cada faixa etária (LI et al., 2019).

O tipo de atividade avaliada também interfere na distância a qual pode estar localizada a área verde. Para o desempenho em leitura, tanto a arborização no terreno da escola quanto a da vizinhança demonstram uma alta relação de influência, enquanto para matemática, esta se dá de forma muito mais significativa quando considerada a vegetação na própria escola (KUO et al., 2018).

O conhecimento a respeito sobre impacto da vegetação no ambiente escolar é de grande relevância para moldar a linha de ação de planejadores urbanos e criadores de políticas públicas. Para reforçar a percepção da importância do contexto em que a escola está inserida (LI et al., 2019).

Se tratando da saúde física, não é necessária uma localização espacial precisa das áreas verdes. Sendo que buffers de 0,5 a $1 \mathrm{~km}$ são os mais eficazes em prever a relação entre ambientes com vegetação e saúde física quando usam a unidade de residência como referência. Enquanto buffers de 1 a 2 km são mais eficazes quando se usa o ponto central da região geográfica - ou bairro - como ponto de partida (BROWNING e LEE, 2017).

Os autores levantam ainda o fato de que raios de estudo criados artificialmente podem não ser a melhor metodologia de prever uma boa distribuição de parques em áreas urbanas. Os sistemas de rastreamento esportivo via GPS possuem dados mais amplos sobre os perfis de deslocamento para a realização de atividade física.

A compreensão dos padrões de deslocamento pode auxiliar no mapeamento dos trechos que possuem maior potencial de uso. Fator que aumentaria a eficácia na implantação de percursos caminháveis.

\subsection{Quantidade e tipo de vegetação}

A tipologia de vegetação e sua extensão podem influenciar diretamente no potencial de um espaço se comportar como uma influência positiva no estado de um indivíduo. Um campus acadêmico com maior cobertura arbórea apresenta uma correlação positiva com o desempenho dos estudantes, enquanto grandes extensões de terra, com paisagens inexpressivas, podem ter resultados de correlação negativa (KWEON et al., 2017).

Comparada a sensação de bem-estar e concentração de um grupo amostral entre 16 e 18 anos, após período de descanso em 3 tipologias de espaço verde, todas apresentam resultado benéfico. Esses espaços foram classificados em pequeno parque urbano, grande parque urbano e floresta. Todavia, enquanto o parque urbano de maior escala foi o que teve impacto mais significativo no desempenho de concentração após o intervalo, a tipologia floresta foi a única que se manteve progressivamente positiva nos testes de autoavaliação de bem-estar (WALLNER et al., 2018).

Outra variante avaliada foi a presença da parede verde dentro da sala de aula. Ela foi relacionada à sensação de bem-estar dos alunos e à percepção de satisfação com a estética da sala, em estudo realizado com alunos entre $5^{\circ}$ e $7^{\circ}$ ano. No entanto, sua presença não demonstrou influência no desempenho em testes de atenção (VAN DEN BERG et al., 2017).

Nem todo tipo de vegetação parece ser positiva para o desempenho. Regiões agrárias, gramados e cobertura vegetal tendem a apresentar resultados nulos ou negativos (LI et al., 2019). De forma geral, árvores demonstram o melhor resultado (BROWNING E RIGOLON, 2019). No entanto, ainda há discordância entre os autores.

A diversidade de espécies de árvores também não parece representar um vínculo significativo com o desempenho escolar, tal como a proporção entre terreno macio e terreno pavimentado. Por outro lado, a tipologia de vegetação - árvores, grama ou cobertura vegetal - possui grande distinção em seu impacto (SIVARAJAH et al., 2018). 


\subsection{Interações e conflitos entre alunos}

Relacionamentos e interações sociais positivas são indispensáveis para a manutenção de indivíduos e comunidades saudáveis. Há fortes indícios de que o comportamento humano sofre influências do ambiente físico (COLEY et al., 1997).

Grandes aglomerações, altas temperaturas e barulho excessivo foram todos ligados a agressividade e violência. Por outro lado, a presença de vegetação parece ter a capacidade de reduzir a hostilidade (KUO e SULLIVAN, 2001).

Apesar de a presença de vegetação já ter sido relacionada à sensação de insegurança, estudos em áreas residenciais com amplo espaço verde encontraram evidências de redução de criminalidade em dados de estatística policial (KUO e SULLIVAN, 2001).

Entre os principais receios associados à presença de árvores em abundância, está a facilidade de um assaltante utilizá-la para se esconder. No entanto, nem todo o tipo de vegetação bloqueia a visão - a exemplo de árvores com copas altas e gramados.

Podemos citar dois conceitos que relacionam a redução de violência à presença de vegetação.

A Teoria de Aumento de Vigilância sugere que um ambiente mais utilizado pela população é mais seguro por ter pessoas observando o que ocorre. A presença de espaço verde pode aumentar a frequência de uso das áreas públicas e semi-públicas. O que consequentemente levaria a interações mais frequentes, maior senso de pertencimento ao local e vigilância (COLEY et al., 1997).

Enquanto a Teoria da Mitigação Psicológica de Precursores para a Violência relaciona a fadiga mental ao aumento da agressividade, sendo que a presença do verde tem capacidade de redução desse cansaço. Os sintomas da fadiga mental podem incluir irritabilidade, falta de atenção e redução do controle sobre impulsos (KAPLAN, 1987).

Em primeiro lugar, a fadiga mental pode contribuir para a agressividade devido aos seus efeitos no processamento cognitivo. O processamento de informações desempenha papel central no gerenciamento de situações sociais, especialmente no de conflitos potenciais (KUO e SULLIVAN, 2001).

Para situações de conflito social, processamentos automáticos - como o de um indivíduo assumir que está sendo injustiçado e tentar se defender - exigem menor esforço do que processamentos reflexivos - como buscar entender qual fator levou ao evento indesejável e mediar a situação para evitar desentendimentos. Em momentos de fadiga mental é mais provável que se use o processamento que requer menor energia, logo, o automático.

A fadiga mental também pode lavar à agressividade por efeitos no estado emocional. Principalmente na elevação da irritabilidade. Indivíduos irritados são mais propensos à agressão quando expostos à frustração.

Por último, a fadiga mental pode levar à agressão pelos seus impactos no comportamento principalmente na redução do controle sobre impulsos. A redução no controle de impulsos tem forte correlação com futuros comportamentos antissociais.

Além de prover sombra e sensação de privacidade, a vegetação - em determinadas conformações possui propriedades calmantes, revigorantes, de redução de irritabilidade e até mesmo de aumento das funções cognitivas (COLEY et al., 1997).

A exemplos de resultados na relação dessas duas teorias, o vandalismo tem uma incidência cerca de 9 vezes menor em locais com vegetação abundante (STAMEN, 1993). 


\subsection{Diferença real de desempenho}

É necessário também que se analise se há conexão de impacto real da presença do verde no cotidiano com o resultado acadêmico.

Uma das análises existentes, sugere como comparativo a soma das variáveis de fatores demográficos, preferência por tipologia de paisagem, estresse e fadiga mental crônicos. Esses fatores alcançaram um montante de $18 \%$ de variação individual de potencial de recuperação de estresse em estudo realizado com 94 alunos de escolas públicas em Illinois (LI e SULLIVAN, 2016).

Enquanto isso, uma janela com vista para paisagem natural teve relação positiva com a recuperação, explicando em $13 \%$ a variação total $(p<0.001)$. Os alunos dessa amostra atingiram 0.7 unidades mais altas no teste, quando comparados aos alunos de salas sem janela ou com vista para barreiras (LI e SULLIVAN, 2016).

Outra análise propõe que a presença de vegetação no ambiente escolar pode explicar em $5,2 \%$ as variações de resultado acadêmico. Valor que é equiparável aos 3 a $6 \%$ de variação atrelados à edificação que abriga a escola (MATSUOKA, 2010).

$\mathrm{Na}$ tabela abaixo, temos o resumo de um estudo de probabilidade de relações de desempenho:

Tabela 1: Tabela de correlações entre habilidades e fatores de influência.

\begin{tabular}{llll}
\hline Habilidade & Influência & Relação & $\begin{array}{l}\text { Probabilidade } \\
\text { de significância }\end{array}$ \\
\hline Desempenho em leitura & Desempenho em matemática & Positiva & $p<0.001$ \\
Desempenho em leitura & Presença de árvores na escola & Positiva & $p<0.001$ \\
Desempenho em leitura & Presença de árvores na vizinhança & Positiva & $p<0.001$ \\
Desempenho em leitura & Presença de gramado & Não significativa & $p>0.1$ \\
Desempenho em leitura & Aluno de baixa renda & Negativa & $p<0.001$ \\
Desempenho em leitura & Proporção de alunos por sala & Não significativa & $p>0.1$ \\
Desempenho em matemática & Desempenho em leitura & Positiva & $p<0.001$ \\
Desempenho em matemática & Presença de árvores na escola & Positiva & $p<0.01$ \\
Desempenho em matemática & Presença de árvores na vizinhança & Positiva & $p<0.05$ \\
Desempenho em matemática & Presença de gramado & Não significativa & $p>0.1$ \\
Desempenho em matemática & Aluno de baixa renda & Negativa & $p<0.001$ \\
Desempenho em matemática & Proporção de alunos por sala & Negativa & $p>0.05$ \\
\hline \multicolumn{2}{c}{ Fonte: Arquivo pessoal, com informações extraídas de Kuo (et al., 2018) } &
\end{tabular}

Ainda não há uma uniformidade entre os autores em relação aos valores encontrados sobre o impacto da presença de área verde. Todavia, a existência desse impacto demonstra forte probabilidade.

\section{Metodologia da Revisão Sistemática}

O processo de revisão sistemática foi adaptado a partir do sistema de Itens Preferidos para Relatórios para Revisões Sistemáticas e Meta-Análises (PRISMA). O sistema, consiste na premissa de análise de um conjunto mínimo de itens e seleção randomizada dos artigos. Dessa forma, pode trazer uma abordagem mais completa e evitar viés na triagem das publicações. Essa metodologia foi escolhida como base por ser amplamente utilizada em artigos sobre pesquisa comportamental.

Há limitações relacionadas ao pequeno número de publicações sobre o tema. A análise de risco de viés deve auxiliar na compreensão do motivo que leva à discordância entre autores e seus resultados. Ela também pode elucidar a respeito de fatores relevantes para pesquisas futuras.

\subsection{Critérios de seleção, fontes de informação e busca}

Para a seleção dos estudos foram adotadas as etapas de identificação de palavras-chave relacionadas ao tema, leitura de títulos e resumos e exclusão, após leitura completa do texto. 
Como base de dados foi utilizada a plataforma de Periódicos Capes, restringindo a pesquisa a artigos revisados em pares. As palavras-chave foram condicionadas como ("school performance" OR "student performance" OR "desempenho escolar"); (vegetation OR vegetação OR greenness); e (estresse OR stress). Foram inclusos na pesquisa os estudos publicados até dezembro de 2019, nos idiomas português e inglês.

Para determinar os critérios de seleção, se preencheu os componentes de pergunta de pesquisa do sistema PICOS. O anagrama se refere a População, Intervenção ou Exposição, Comparação, Desfecho (outcome) e Tipo do estudo (study type) (GALVÃO e PEREIRA, 2014).

A escolha da população está relacionada ao potencial de desenvolvimento acadêmico, logo inclui jovens até o ensino superior. Deve haver exposição a presença de vegetação e é pretendido comparar seus efeitos por faixa etária, momento de contato com a vegetação, tipo de vegetação presente no estudo e a distância da área verde em relação ao indivíduo. O desfecho deve avaliar os efeitos em performance acadêmica ou testes cognitivos. Serão aceitos estudos do tipo experimental e observacional.

\subsection{Processo de coleta de dados, lista de dados e síntese de resultados}

As informações foram extraídas e inseridas em tabela Excel. Essa foi preenchida com dados de citação, dimensão de amostra, público analisado por faixa etária, tipo de vegetação, posição da vegetação, estação do ano em que ocorreu a coleta de amostra para a pesquisa, momento de contato com o verde, fator analisado e resultado de cada estudo.

\subsection{Avaliação da qualidade metodológica dos estudos}

Classificou-se os estudos entre observacional e experimental.

\section{Resultados}

\subsection{Seleção dos estudos}

O resultado inicial foi de 111 artigos. Dessa amostra, 3 foram eliminados por repetição e 74 por apresentarem inconsistência com o tema - identificada no título ou resumo. Após a leitura completa dos artigos restantes, foram descartados outros 16 por não contemplarem as informações listadas no PICOS ou necessárias para o preenchimento mínimo da tabela 2.

Ao final, restaram 18 artigos para integrar a revisão.

\subsection{Características dos estudos}

Devido a heterogeneidade dos artigos obtidos no processo, optou-se por apresentar os resultados de cada um em tabela (PEREIRA e GALVÃO, 2014).

Os estudos foram publicados majoritariamente nos últimos anos, fator que indica o aumento no interesse pelo assunto. Entre 18 pesquisas, 15 foram estão datadas entre 2017 e 2019. As dimensões de amostra em nível institucional representam 12 dos artigos e variam de 6 creches a 1789 escolas, em nível individual representam 6 estudos, com 64 a 1932 participantes.

Quanto à faixa etária considerada nos estudos, 4 artigos tratavam sobre bebês ou crianças em idade pré-escolar, 12 sobre jovens em idade de ensino fundamental, 6 sobre jovens em idade de ensino médio, 1 sobre universitários e 1 sobre idosos. Fatores que influenciaram na percepção de relação da posição da área verde relevante com a idade do grupo amostral.

As coletas de dados se originaram nos Estados Unidos $(n=9)$, China $(n=2)$, Escócia, Finlândia, Áustria, Holanda, Alemanha, Espanha e Canadá. Todas ocorreram em pontos localizados no 
hemisfério norte e acima do trópico de câncer. Fator que indica uma limitação na diversidade de culturas e espécies vegetais observadas.

Quanto à qualidade metodológica dos estudos, 15 foram identificados como observacionais e apenas 3 como experimentais (Puhakka et al., 2019; Wallner et al., 2018; van Den Berg et al., 2017). 
Quadro 1: Resultado da revisão sistemática

\begin{tabular}{|c|c|c|c|c|c|c|c|c|}
\hline Citação & $\begin{array}{l}\text { Dimensão } \\
\text { de amostra }\end{array}$ & Faixa etária & $\begin{array}{l}\text { Tipo de } \\
\text { Vegetação }\end{array}$ & $\begin{array}{l}\text { Posição da } \\
\text { Vegetação }\end{array}$ & $\begin{array}{l}\text { Estação } \\
\text { do ano }\end{array}$ & $\begin{array}{l}\text { Momento de } \\
\text { Contato }\end{array}$ & Fator analisado & Resultados \\
\hline Li et al. (2019) & 624 escolas & Ensino médio & $\begin{array}{l}\text { Cobertura } \\
\text { por copas } \\
\text { de árvores }\end{array}$ & $\begin{array}{l}\text { Buffers de } 0,4 \text {, } \\
0,8,1,6,3,2 \text { e } 4,8 \\
\text { km a partir da } \\
\text { escola }\end{array}$ & $\begin{array}{l}\text { Não } \\
\text { consta }\end{array}$ & $\begin{array}{l}\text { Vivência } \\
\text { cotidiana }\end{array}$ & $\begin{array}{l}\text { Teste admissional em } \\
\text { universidade, preparo } \\
\text { para a universidade, } \\
\text { desempenho no início } \\
\text { do ensino médio e } \\
\text { conclusão do ensino } \\
\text { médio no tempo } \\
\text { esperado }\end{array}$ & $\begin{array}{l}\text { Relação positiva em todas as } \\
\text { distâncias para teste admissional e } \\
\text { exceto } 3,2 \mathrm{~km} \text { para preparo no início do } \\
\text { ensino médio. Demais fatores não } \\
\text { foram relacionáveis. }\end{array}$ \\
\hline Leung et al. (2019) & $\begin{array}{l}1789 \\
\text { escolas }\end{array}$ & $\begin{array}{l}\text { Ensino } \\
\text { fundamental e } \\
\text { médio }\end{array}$ & $\begin{array}{l}\text { NDVI e } \\
\text { área de uso } \\
\text { do verde } \\
\text { (florestas / } \\
\text { parques) }\end{array}$ & $\begin{array}{l}\text { Buffers de } 0,25 \\
0,5,1 \text { e } 2 \mathrm{~km} \text { a } \\
\text { partir da escola }\end{array}$ & $\begin{array}{l}\text { Primavera } \\
\text { e outono }\end{array}$ & $\begin{array}{l}\text { Vivência } \\
\text { cotidiana }\end{array}$ & $\begin{array}{l}\text { Língua inglesa e } \\
\text { matemática }\end{array}$ & $\begin{array}{l}\text { Relação positiva em todas as } \\
\text { distâncias para língua inglesa e } \\
\text { matemática, exceto uso de área verde } \\
\text { com buffer de } 0,25 \mathrm{~km} \text { para língua } \\
\text { inglesa. Resultados mais significativos } \\
\text { na primavera. }\end{array}$ \\
\hline Cherrie et al. (2019) & $\begin{array}{l}281 \\
\text { participantes }\end{array}$ & $\begin{array}{l}4 \text { a } 18 \text { anos, } \\
\text { com avaliação } \\
\text { de resultados } \\
\text { aos } 70 \text { e } 76 \\
\text { anos }\end{array}$ & $\begin{array}{l}\text { Parques } \\
\text { públicos na } \\
\text { vizinhança }\end{array}$ & $\begin{array}{l}\text { Buffer de } 1,5 \mathrm{~km} \\
\text { a partir da } \\
\text { residência }\end{array}$ & $\begin{array}{l}\text { Não } \\
\text { consta }\end{array}$ & $\begin{array}{l}\text { Contato ativo } \\
\text { no percurso } \\
\text { para a escola }\end{array}$ & $\begin{array}{l}\text { Capacidade cognitiva } \\
\text { em idade avançada, } \\
\text { pela interação com } \\
\text { parques na infância e } \\
\text { adolescência. }\end{array}$ & $\begin{array}{l}\text { Relação positiva da presença de } \\
\text { parques com capacidade cognitiva. } \\
\text { Mais significativa na adolescência. }\end{array}$ \\
\hline $\begin{array}{l}\text { Puhakka et al. } \\
\text { (2019) }\end{array}$ & 6 creches & De 3 a 5 anos & $\begin{array}{l}\text { Vegetação } \\
\text { diversa }\end{array}$ & $\begin{array}{l}\text { Terreno da } \\
\text { escola }\end{array}$ & $\begin{array}{l}\text { Não } \\
\text { consta }\end{array}$ & $\begin{array}{l}\text { Contato ativo } \\
\text { com a } \\
\text { vegetação e } \\
\text { o solo }\end{array}$ & $\begin{array}{l}\text { Estímulo } \\
\text { multisensorial }\end{array}$ & $\begin{array}{l}\text { Relação positiva com nível de atividade } \\
\text { física e sua diversidade, melhoras no } \\
\text { humor, energia e motivação. }\end{array}$ \\
\hline Liao et al. (2019) & $\begin{array}{l}1312 \\
\text { gestantes }\end{array}$ & $\begin{array}{l}\text { Entre a } \\
\text { gestação e os } 2 \\
\text { anos }\end{array}$ & NDVI & $\begin{array}{l}\text { Buffers de } 0,3 \text {, } \\
0,5 \text { e } 1 \mathrm{~km} \text { a } \\
\text { partir da } \\
\text { residência }\end{array}$ & $\begin{array}{l}\text { Não } \\
\text { consta }\end{array}$ & $\begin{array}{l}\text { Vivência } \\
\text { cotidiana }\end{array}$ & $\begin{array}{l}\text { Teste psicomotor e } \\
\text { desenvolvimento } \\
\text { mental em bebês }\end{array}$ & $\begin{array}{l}\text { Relação positiva em resultado de teste } \\
\text { psicomotor e desenvolvimento mental. }\end{array}$ \\
\hline Liu et al. (2018) & $\begin{array}{l}8 \\
\text { instituições }\end{array}$ & Universidade & $\begin{array}{l}\text { Vegetação } \\
\text { diversa }\end{array}$ & $\begin{array}{l}\text { Campus da } \\
\text { universidade }\end{array}$ & $\begin{array}{l}\text { Não } \\
\text { consta }\end{array}$ & $\begin{array}{l}\text { Contato ativo } \\
\text { em visita à } \\
\text { área verde } \\
\text { do campus }\end{array}$ & $\begin{array}{l}\text { Percepção de } \\
\text { naturalidade do } \\
\text { ambiente relacionada } \\
\text { a efeitos restaurativos } \\
\text { e de melhora na saúde }\end{array}$ & $\begin{array}{l}\text { Relação positiva para autoavaliação de } \\
\text { restauração e melhora na saúde. }\end{array}$ \\
\hline
\end{tabular}


Quadro 1: Resultado da revisão sistemática

\begin{tabular}{|c|c|c|c|c|c|c|c|c|}
\hline Citação & $\begin{array}{l}\text { Dimensão } \\
\text { de amostra }\end{array}$ & Faixa etária & $\begin{array}{l}\text { Tipo de } \\
\text { Vegetação }\end{array}$ & $\begin{array}{l}\text { Posição da } \\
\text { Vegetação }\end{array}$ & $\begin{array}{l}\text { Estação } \\
\text { do ano }\end{array}$ & $\begin{array}{l}\text { Momento de } \\
\text { Contato }\end{array}$ & Fator analisado & Resultados \\
\hline Kuo et al. (2018) & 318 escolas & $\begin{array}{l}\text { Ensino } \\
\text { fundamental }\end{array}$ & $\begin{array}{l}\text { Árvores e } \\
\text { gramado }\end{array}$ & $\begin{array}{l}\text { Terreno da } \\
\text { escola e sua } \\
\text { vizinhança }\end{array}$ & $\begin{array}{l}\text { Não } \\
\text { consta }\end{array}$ & $\begin{array}{l}\text { Vivência } \\
\text { cotidiana }\end{array}$ & Leitura e matemática & $\begin{array}{l}\text { Relação positiva de presença de } \\
\text { árvores em ambas as posições de } \\
\text { vegetação com leitura e matemática. A } \\
\text { presença de gramado não foi } \\
\text { significativa. }\end{array}$ \\
\hline $\begin{array}{l}\text { Sivarajah et al. } \\
\text { (2018) }\end{array}$ & 387 escolas & $\begin{array}{l}\text { Ensino } \\
\text { fundamental }\end{array}$ & $\begin{array}{l}\text { Árvores, } \\
\text { gramado e } \\
\text { cobertura } \\
\text { vegetal }\end{array}$ & $\begin{array}{l}\text { Terreno da } \\
\text { escola }\end{array}$ & $\begin{array}{l}\text { Não } \\
\text { consta }\end{array}$ & $\begin{array}{l}\text { Vivência } \\
\text { cotidiana }\end{array}$ & $\begin{array}{l}\text { Relação entre área de } \\
\text { cobertura de árvores, } \\
\text { diversidade e espécies } \\
\text { de vegetação com seu } \\
\text { impacto no } \\
\text { desempenho. }\end{array}$ & $\begin{array}{l}\text { Relação positiva entre cobertura por } \\
\text { árvore e desempenho em testes de } \\
\text { alunos de } 6^{\mathrm{a}} \text { série, mas não com os de } \\
3^{\mathrm{a}} \text { série. Áreas gramadas, cobertura } \\
\text { vegetal e diversidade de espécies não } \\
\text { apresentaram relação significativa com } \\
\text { o desempenho. }\end{array}$ \\
\hline Wallner et al. (2018) & 64 alunos & Ensino médio & $\begin{array}{l}\text { Parque } \\
\text { pequeno, } \\
\text { parque } \\
\text { grande e } \\
\text { floresta }\end{array}$ & $\begin{array}{l}\text { Percurso de } \\
\text { caminhada e } \\
\text { descanso }\end{array}$ & $\begin{array}{l}\text { Não } \\
\text { consta }\end{array}$ & $\begin{array}{l}\text { Contato ativo } \\
\text { no horário de } \\
\text { almoço }\end{array}$ & $\begin{array}{l}\text { Capacidade } \\
\text { restaurativa }\end{array}$ & $\begin{array}{l}\text { Relação positiva das } 3 \text { tipologias com } \\
\text { a concentração. As relações de bem- } \\
\text { estar se mantiveram positivas de forma } \\
\text { constante apenas para a floresta. }\end{array}$ \\
\hline Tallis et al. (2018) & 495 escolas & $\begin{array}{l}\text { Ensino } \\
\text { fundamental }\end{array}$ & $\begin{array}{l}\mathrm{NDVI}, \\
\text { agricultura, } \\
\text { árvores e } \\
\text { arbustos }\end{array}$ & $\begin{array}{l}\text { Buffers de } 10, \\
50,100,300,500 \\
\text { e } 750 \text { metros e } \\
1 \mathrm{~km}\end{array}$ & $\begin{array}{l}\text { Verão, em } \\
\text { período } \\
\text { seco }\end{array}$ & $\begin{array}{l}\text { Vivência } \\
\text { cotidiana }\end{array}$ & $\begin{array}{l}\text { Leitura, escrita e } \\
\text { matemática }\end{array}$ & $\begin{array}{l}\text { Relação positiva da cobertura por } \\
\text { árvores e arbustos em área urbana } \\
\text { apenas para buffers de } 0,75 \text { e } 1 \mathrm{~km} \text {. A } \\
\text { presença de agricultura anulou os } \\
\text { resultados de relação positiva com } \\
\text { área verde. NDVI não apresentou } \\
\text { relação. }\end{array}$ \\
\hline $\begin{array}{l}\text { Hodson \& Sander } \\
(2017)\end{array}$ & 222 escolas & $\begin{array}{l}\text { Ensino } \\
\text { fundamental }\end{array}$ & $\begin{array}{l}\text { Árvores, } \\
\text { arbustos e } \\
\text { gramado }\end{array}$ & $\begin{array}{l}\text { Na região da } \\
\text { escola e da } \\
\text { residência }\end{array}$ & $\begin{array}{l}\text { Não } \\
\text { consta }\end{array}$ & $\begin{array}{l}\text { Vivência } \\
\text { cotidiana }\end{array}$ & Leitura e matemática & $\begin{array}{l}\text { Relação positiva entre árvores e o } \\
\text { desempenho em leitura e relação } \\
\text { inversa entre superfícies impermeáveis } \\
\text { e leitura. Demais fatores não foram } \\
\text { significativos. }\end{array}$ \\
\hline $\begin{array}{l}\text { van Den Berg et al. } \\
(2017)\end{array}$ & 170 alunos & $\begin{array}{l}\text { Ensino } \\
\text { fundamental }\end{array}$ & $\begin{array}{l}\text { Parede } \\
\text { verde }\end{array}$ & Sala de aula & $\begin{array}{l}\text { Não } \\
\text { consta }\end{array}$ & $\begin{array}{l}\text { Vivência } \\
\text { cotidiana }\end{array}$ & $\begin{array}{l}\text { Teste de atenção e } \\
\text { autoavaliação de bem- } \\
\text { estar }\end{array}$ & $\begin{array}{l}\text { Relação positiva apenas para } \\
\text { autoavaliação de bem-estar. }\end{array}$ \\
\hline
\end{tabular}

Fonte: Arquivo pessoal 
Quadro 1: Resultado da revisão sistemática

\begin{tabular}{|c|c|c|c|c|c|c|c|c|}
\hline Citação & $\begin{array}{l}\text { Dimensão } \\
\text { de amostra }\end{array}$ & Faixa etária & $\begin{array}{l}\text { Tipo de } \\
\text { Vegetação }\end{array}$ & $\begin{array}{l}\text { Posição da } \\
\text { Vegetação }\end{array}$ & $\begin{array}{l}\text { Estação } \\
\text { do ano }\end{array}$ & $\begin{array}{l}\text { Momento de } \\
\text { Contato }\end{array}$ & Fator analisado & Resultados \\
\hline $\begin{array}{l}\text { Dadvand et al. } \\
\text { (2017) }\end{array}$ & $\begin{array}{l}1527 \\
\text { crianças }\end{array}$ & $\begin{array}{l}\text { Grupo amostral } \\
\text { ao nascimento, } \\
\text { com teste aos } 4 \\
\text { ou } 5 \text { anos e aos } \\
7 \text { anos }\end{array}$ & $\begin{array}{l}\text { NDVI e } \\
\text { cobertura } \\
\text { por copas } \\
\text { de árvores }\end{array}$ & $\begin{array}{l}\text { Buffers de } 0,1 \\
0,3 \text { e } 0,5 \mathrm{~km} \text { a } \\
\text { partir da } \\
\text { residência }\end{array}$ & $\begin{array}{l}\text { Não } \\
\text { consta }\end{array}$ & $\begin{array}{l}\text { Vivência } \\
\text { cotidiana }\end{array}$ & $\begin{array}{l}\text { Teste de atenção (K- } \\
\text { CPT e ANT) para erros } \\
\text { de omissão, erros de } \\
\text { comissão e } \\
\text { consistência no tempo } \\
\text { de resposta }\end{array}$ & $\begin{array}{l}\text { Relação para NDVI com redução nos } \\
\text { erros de omissão e melhora no tempo } \\
\text { de resposta em teste K-PCT. Para o } \\
\text { teste ANT, apenas a cobertura por } \\
\text { copa de árvore teve relação positiva } \\
\text { com a redução no tempo de resposta e } \\
\text { apenas no buffer de } 0,5 \mathrm{~km} \text {. Demais } \\
\text { fatores não foram significativos. }\end{array}$ \\
\hline $\begin{array}{l}\text { Macnaughton et al. } \\
\text { (2017) }\end{array}$ & $\begin{array}{l}1772 \\
\text { escolas }\end{array}$ & $\begin{array}{l}\text { Ensino } \\
\text { fundamental }\end{array}$ & NDVI & $\begin{array}{l}\text { Trecho entre } \\
0,25 \text { e } 1 \mathrm{~km} \text { a } \\
\text { partir da escola }\end{array}$ & $\begin{array}{l}\text { Não } \\
\text { consta }\end{array}$ & $\begin{array}{l}\text { Vivência } \\
\text { cotidiana }\end{array}$ & Falta crônica às aulas & $\begin{array}{l}\text { Relação inversa entre nível de NDVI e } \\
\text { faltas crônicas. }\end{array}$ \\
\hline Kweon et al. (2017) & 219 escolas & $\begin{array}{l}\text { Ensino } \\
\text { fundamental e } \\
\text { médio }\end{array}$ & $\begin{array}{l}\text { Árvores e } \\
\text { arbustos } \\
\text { ou } \\
\text { gramado }\end{array}$ & $\begin{array}{l}\text { Terreno da } \\
\text { escola }\end{array}$ & $\begin{array}{l}\text { Não } \\
\text { consta }\end{array}$ & $\begin{array}{l}\text { Vivência } \\
\text { cotidiana }\end{array}$ & Leitura e matemática & $\begin{array}{l}\text { Relação positiva apenas para árvores } \\
\text { no desempenho em leitura e } \\
\text { matemática. Arbustos e gramado não } \\
\text { foram significativos. }\end{array}$ \\
\hline $\begin{array}{l}\text { Markevych et al. } \\
\text { (2014) }\end{array}$ & $\begin{array}{l}1932 \\
\text { participantes }\end{array}$ & $\begin{array}{l}\text { Ensino } \\
\text { fundamental }\end{array}$ & $\begin{array}{l}\text { Espaço } \\
\text { verde } \\
\text { (parques / } \\
\text { jardins) }\end{array}$ & $\begin{array}{l}\text { Buffers de } 0,3 \text { a } \\
0,5 \mathrm{~km} \text { a partir } \\
\text { da residência }\end{array}$ & Verão & $\begin{array}{l}\text { Vivência } \\
\text { cotidiana }\end{array}$ & $\begin{array}{l}\text { Incidência de } \\
\text { hiperatividade e } \\
\text { problemas de atenção }\end{array}$ & $\begin{array}{l}\text { Relação de aumento na taxa de } \\
\text { problemas de hiperatividade e atenção } \\
\text { quando a distância do espaço verde é } \\
\text { superior a } 0,5 \mathrm{~km} \text { da residência. }\end{array}$ \\
\hline Wu et al. (2014) & 905 escolas & $\begin{array}{l}\text { Ensino } \\
\text { fundamental }\end{array}$ & NDVI & $\begin{array}{l}\text { Buffers de } 0,25 \\
0,5,1 \text { e } 2 \mathrm{~km} \text { a } \\
\text { partir da escola }\end{array}$ & $\begin{array}{l}\text { Primavera, } \\
\text { verão e } \\
\text { outono }\end{array}$ & $\begin{array}{l}\text { Vivência } \\
\text { cotidiana }\end{array}$ & $\begin{array}{l}\text { Língua inglesa e } \\
\text { matemática }\end{array}$ & $\begin{array}{l}\text { Relação positiva para todas as } \\
\text { dimensões de buffer, sendo mais } \\
\text { significativa durante a primavera. }\end{array}$ \\
\hline Matsuoka (2010) & 101 escolas & Ensino médio & $\begin{array}{l}\text { Árvores, } \\
\text { arbustos e } \\
\text { gramado }\end{array}$ & $\begin{array}{l}\text { Terreno da } \\
\text { escola }\end{array}$ & $\begin{array}{l}\text { Não } \\
\text { consta }\end{array}$ & $\begin{array}{l}\text { Contato } \\
\text { passivo } \\
\text { durante as } \\
\text { atividades e } \\
\text { ativo nos } \\
\text { intervalos }\end{array}$ & $\begin{array}{l}\text { Premiação de mérito, } \\
\text { notas escolares e } \\
\text { conclusão do ensino } \\
\text { médio no tempo } \\
\text { esperado }\end{array}$ & $\begin{array}{l}\text { Relação positiva para contato nos } \\
\text { intarvalos. Exposição a ambiente } \\
\text { natural durante atividades não gerou } \\
\text { resultado. }\end{array}$ \\
\hline
\end{tabular}


Os principais métodos de identificação de presença de manchas verdes utilizados foram de cobertura por copa de árvore $(n=8)$ e Índice de Vegetação com Diferença Normalizada (NDVI) $(n=6)$.

\subsection{Risco de viés}

Devido às características de heterogeneidade entre as pesquisas analisadas, não foi possível realizar um gráfico de funil. As recomendações para tal são de amostras superiores a 10 estudos de mesma metodologia e apenas 6 se enquadraram em parâmetros minimamente compatíveis (PEREIRA e GALVÃO, 2014). Portanto, foram evidenciados elementos que geram risco de viés através de diferenças estruturais.

Um dos fatores observados foi que nem todos os autores apresentam o resultado individual de cada buffer. Situação que pode omitir amostras não significativas. O mesmo ocorre com amostras de faixas etárias diferentes que apresentaram seu resultado de dados mesclado.

Outro possível viés surge quando comparados os tipos de análise de presença de vegetação. Alguns autores (SIVARAJAH et al., 2018) (HODSON e SANDER, 2017) apontam que tipologias de vegetação possuem níveis diferentes de relação com o desempenho. Nos artigos revisados foi mais recorrente a existência de significância estatística para árvores quando comparadas a gramados. Logo, dados baseados em NDVI, podem ter resultados de correlação mais irregular. Nesse método a maioria dos pesquisadores não diferencia o tipo de vegetação, se limitando a apontar se há ou não presença dessa.

Há também uma relação entre a época do ano e o potencial de impacto da vegetação sobre o desempenho (LEUNG et al., 2019) (WU et al., 2014). Esse fator pode ser associado à deciduidade natural da espécie ou período de estiagem. A área de cobertura vegetal identificada por NDVI pode variar ao longo do ano. Como esse fator foi pouco verificado pelos os autores, as condições climáticas em que foi desenvolvida a pesquisa pode causar uma má interpretação dos resultados.

\subsection{Resultados de estudos individuais}

Para melhor compreensão dos resultados como um todo, as informações foram resumidas na tabela 2, cruzando os dados de Fator Analisado com seus resultados para cada Posição e Tipo de Vegetação.

Em cada linha e coluna foram somados todos os estudos dentro das mesmas características. O resultado do cruzamento entre eles representa o número de estudos que encontraram correlação significativa positiva (+), não significativa (0) ou significativa negativa (-).

Por facilitar a leitura da síntese, alguns dados foram reunidos por características de semelhança. $O$ item linguagem compreende os dados para desempenho em inglês, escrita e leitura. Desempenho escolar reúne os dados para desempenho no início do ensino médio, conclusão desse no tempo esperado, premiação de mérito e notas escolares não discriminadas por matéria. Ingresso ao ensino superior abrange teste admissional e índice de preparo para a faculdade. Por último, desenvolvimento infantil resume as avaliações de neurodesenvolvimento, habilidade psicomotora e avaliação de atenção na primeira infância.

Capacidade cognitiva em idade avançada - por influências na infância e adolescência - e faltas crônicas não foram inclusas na síntese por serem fatores com uma única análise dentro da amostra. Ambos apresentaram correlação positiva com a presença de vegetação 
Tabela 2: Síntese de resultado de cada estudo

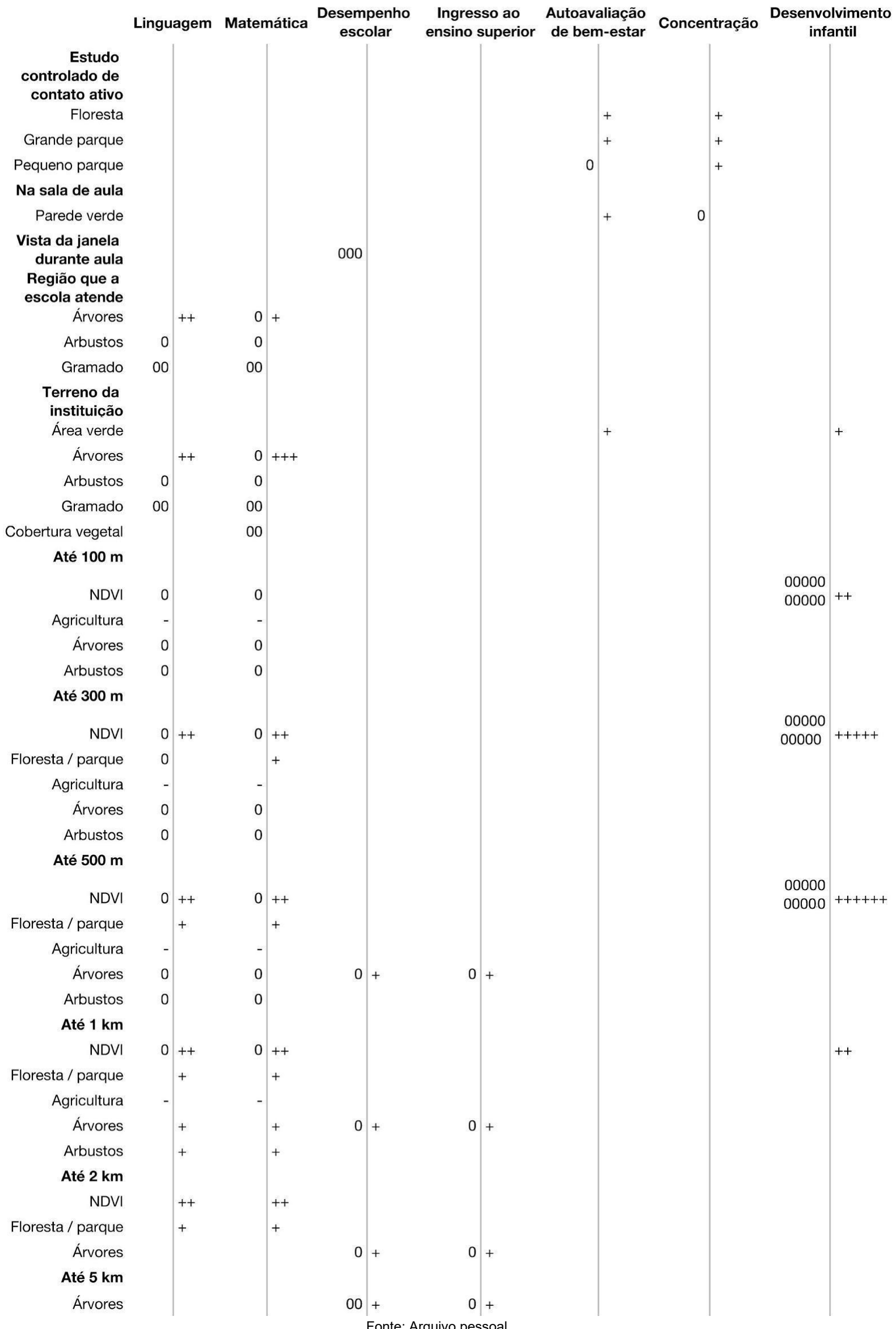




\subsection{Análises adicionais}

A respeito da dimensão de buffer efetivo, Li et al. (2019) levanta a possibilidade de uma variação na relação que as faixas etárias têm com o meio urbano. A independência para circular pela cidade se altera muito quando comparados crianças e adolescentes. Os estudos apontam que crianças tendem a ter uma relação mais relevante com o espaço natural que se encontra nas imediações da escola ou residência. Por outro lado, estudos realizados com adolescentes identificaram um vínculo entre desempenho e vegetação em um raio de até $4,8 \mathrm{~km}$ de distância do ponto avaliado.

Esse fator foi reforçado por Cherrie et al. (2019), que avaliou o efeito da presença de parques próximos à residência na infância e adolescência e seus impactos na capacidade cognitiva após os 70 anos. Os adolescentes se beneficiaram mais desse recurso urbano.

Foi identificou uma correlação negativa entre a presença de árvores e a proporção de alunos considerados em desvantagem - com baixa renda familiar e de minorias étnicas (KUO et al., 2018). Aspecto que contribui para os distanciamentos entre a qualidade de ensino público e privado.

Amostras com faixas etárias diferentes apresentaram uma relação de resultados que varia quanto à dimensão mais efetiva de buffer para a área de inclusão na pesquisa. O que condiz com o observado quando os autores encontraram resultados diferentes para a validade buffer.

Sivarajah et al. (2018), por exemplo, encontrou relação significativa entre a presença de árvores no terreno da escola e o desempenho acadêmico para alunos de $6^{\mathrm{a}}$ série, mas não para alunos de $3^{\mathrm{a}}$ série. Em análise do impacto da presença de parques urbanos - ao longo da infância e adolescência - na capacidade cognitiva na terceira idade, adolescentes apresentaram maior influência.

\section{Discussão}

O objetivo desta revisão sistemática era compreender de que forma a vegetação poderia impactar na performance acadêmica e no desenvolvimento do aluno. Foram identificadas 142 análises em 18 publicações que se enquadraram nos critérios de seleção.

Essas análises apontaram para as seguintes tendências: elementos que remetem à maior naturalidade do espaço - árvores, parques e florestas - apresentam uma correlação mais evidente com o desempenho. Gramados e áreas de cobertura vegetal foram pouco relacionados ao resultado esperado.

Também é mais visível o impacto do espaço verde em fatores de análise mais específica - como linguagem, matemática ou resultado em testes de atenção. Temáticas com variáveis mais complexas como conclusão do ensino médio em tempo esperado e desempenho acadêmico generalizado tendem a ter maior relação com o contexto familiar e social. Essas podem ainda perder significância estatística por mascararem outras variáveis que, de fato, não se relacionam ao espaço verde.

Quanto a falta de evidências para o buffer de $0,1 \mathrm{~km}$, é importante ressaltar que os raios de estudo maiores são todos sobrepostos e inclusivos quanto à sua área de abrangência. Esse dado não aponta para uma irrelevância da vegetação mais próxima, mas pode estar relacionado a uma uniformidade superior de distribuição de área verde encontrada em amostras maiores. Por outro lado, essa informação realmente aponta que buffers pequenos têm menor chance de prever resultados.

A comparação entre resultados do estudo sobre vista a partir da janela (MATSUOKA, 2010) e presença de parede verde na sala (VAN DEN BERG et al., 2017) com o contato em momento de 
intervalo (MATSUOKA, 2010) e horário de almoço (WALLNER et al., 2018) reforça novamente as recomendações da Teoria de Restauração da Atenção.

Visto que há relação entre menor área verde em locais com mais alunos de baixa renda (KUO et al., 2018), o uso do Sistema de Informações Geográficas pode contribuir no planejamento prévio para mitigar essa diferença. O recurso, junto a uma proposta de Desenvolvimento Orientado ao Transporte, pode auxiliar a traçar o melhor posicionamento da unidade escolar. Tudo isso através do mapeamento de melhores recursos de área verde e viabilização de percursos transcorríveis a pé. Combinação essa que, como apresentado, pode ter repercussão positiva até na capacidade cognitiva em idade avançada (CHERRIE et al., 2019).

Por último, é relevante ressaltar as limitações na variedade de regiões de origem para os artigos revisados. Pesquisas realizados em áreas de clima quente e vegetação tropical podem, bem como em contexto sociocultural diverso, apresentar novos formatos de relação com o espaço verde. Podese considerar fatores como uso contínuo da área externa - devido às características de ausência de clima frio e relações de interação social com características próprias.

Por se tratar de uma temática com poucas publicações, optou-se optou por analisar estudos com objetivos diferentes. Parte das pesquisas se baseia em dados de autoavaliação e a maioria dos estudos foi do tipo observacional. Esses elementos dificultaram a criação de um gráfico mais sólido de comparações. As observações de variáveis de confusão identificados também contribuem para as limitações na qualidade metodológica.

\subsection{Pesquisas futuras}

Foi identificada a necessidade de futuras pesquisas reunirem em um único estudo as variáveis de confusão identificadas. Incluindo além dos usuais fatores de renda do grupo amostral e etnia. Informações de tipologia de vegetação, comparação de épocas do ano e relação de diferentes faixas etárias - analisadas separadamente - foram pouco exploradas.

Há pouco material avaliando a relação entre vegetação como causa indireta da variação na performance acadêmica. A recorrência de bullying, por exemplo, é relacionada a queda no desempenho escolar do agressor (SOUZA et al., 2017). Sendo que a vegetação, por sua vez, é associada a um melhor controle sobre impulsos e redução na irritabilidade.

Também é relevante a produção de estudos experimentais e analíticos, visto que o material encontrado é predominantemente observacional e em grande parte descritivo. Fator que reduz a força de evidência das informações.

É imprescindível, ainda, estudar o impacto da presença do verde em regiões e contextos diversos.

\section{Conclusões}

Essa revisão demonstrou que há fortes evidências de correlação entre a presença de vegetação e o desempenho acadêmico. Em especial quando há contato ativo com o espaço natural durante intervalos entre atividade, quando a vegetação se encontra dentro do terreno da instituição de ensino e em buffers sobrepostos de 250 metros até 1 quilômetro.

\section{Referências bibliográficas:}


ALVARES, Sandra Leonora et al. Programando a arquitetura escolar: a relação entre ambientes de aprendizagem, comportamento humano no ambiente construído e teorias pedagógicas. 2016.

ALVES, Maria Teresa Gonzaga et al. Fatores familiares e desempenho escolar: uma abordagem multidimensional. DADOS-Revista de Ciências Sociais, v. 56, n. 3, p. 571-603, 2013.

Brasil, Instituto Nacional de Estudos e Pesquisas Educacionais Anísio Teixeira. Relatório Pedagógico: Enem 2011-2012 - Brasília, DF: Inep, 2015.

BROWNING, Matthew HEM; RIGOLON, Alessandro. School green space and its impact on academic performance: A systematic literature review. International journal of environmental research and public health, v. 16, n. 3, p. 429, 2019.

BROWNING, Matthew; LEE, Kangjae. Within what distance does "greenness" best predict physical health? A systematic review of articles with GIS buffer analyses across the lifespan. International journal of environmental research and public health, v. 14, n. 7, p. 675, 2017.

CHERRIE, Mark PC et al. Association between the activity space exposure to parks in childhood and adolescence and cognitive aging in later life. International journal of environmental research and public health, v. 16, n. 4, p. 632, 2019.

COLEY, Rebekah Levine; SULLIVAN, William C.; KUO, Frances E. Where does community grow? The social context created by nature in urban public housing. Environment and behavior, v. 29, n. 4, p. 468-494, 1997.

DADVAND, Payam et al. Lifelong residential exposure to green space and attention: a populationbased prospective study. Environmental health perspectives, v. 125, n. 9, p. 097016, 2017.

EVANS, Gary W. Child development and the physical environment. Annu. Rev. Psychol., v. 57, p. 423-451, 2006.

GALVÃO, Taís Freire; PANSANI, Thais de Souza Andrade; HARRAD, David. Principais itens para relatar Revisões sistemáticas e Meta-análises: A recomendação PRISMA. Epidemiologia e Serviços de Saúde, v. 24, p. 335-342, 2015.

GALVÃO, Taís Freire; PEREIRA, Mauricio Gomes. Avaliação da qualidade da evidência de revisões sistemáticas. Epidemiologia e Serviços de Saúde, v. 24, p. 173-175, 2015.

GALVÃO, Taís Freire; PEREIRA, Mauricio Gomes. Revisões sistemáticas da literatura: passos para sua elaboração. Epidemiologia e Serviços de Saúde, v. 23, p. 183-184, 2014.

HODSON, Cody B.; SANDER, Heather A. Green urban landscapes and school-level academic performance. Landscape and Urban Planning, v. 160, p. 16-27, 2017.

JIANG, Bin et al. A dose-response curve describing the relationship between urban tree cover density and self-reported stress recovery. Environment and behavior, v. 48, n. 4, p. 607-629, 2016.

JIANG, Bin; SCHMILLEN, Rose; SULLIVAN, William C. How to waste a break: Using portable electronic devices substantially counteracts attention enhancement effects of green spaces. Environment and Behavior, v. 51, n. 9-10, p. 1133-1160, 2019.

JOHNSON, Shannon A. et al. Quasi-randomized trial of contact with nature and effects on attention in children. Frontiers in psychology, v. 10, p. 2652, 2019. 
KAPLAN, Stephen. Aesthetics, affect, and cognition: Environmental preference from an evolutionary perspective. Environment and behavior, v. 19, n. 1, p. 3-32, 1987.

KAPLAN, Stephen. The restorative benefits of nature: Toward an integrative framework. Journal of environmental psychology, v. 15, n. 3, p. 169-182, 1995.

KUO, Frances E.; SULLIVAN, William C. Aggression and violence in the inner city: Effects of environment via mental fatigue. Environment and behavior, v. 33, n. 4, p. 543-571, 2001.

KUO, Frances E.; SULLIVAN, William C. Environment and crime in the inner city: Does vegetation reduce crime?. Environment and behavior, v. 33, n. 3, p. 343-367, 2001.

KUO, Ming; BROWNING, Matthew HEM; PENNER, Milbert L. Do lessons in nature boost subsequent classroom engagement? Refueling students in flight. Frontiers in psychology, v. 8, p. 2253, 2018.

KUO, Ming et al. Might school performance grow on trees? Examining the link between "greenness" and academic achievement in urban, high-poverty schools. Frontiers in psychology, v. 9, p. 1669, 2018.

KWEON, Byoung-Suk et al. The link between school environments and student academic performance. Urban Forestry \& Urban Greening, v. 23, p. 35-43, 2017.

LEUNG, Wing Tuen Veronica et al. How is environmental greenness related to students' academic performance in English and mathematics?. Landscape and Urban Planning, v. 181, p. 118-124, 2019.

LI, Dongying et al. Beyond the school grounds: Links between density of tree cover in school surroundings and high school academic performance. Urban forestry \& urban greening, v. 38, p. 42-53, 2019.

LI, Dongying; SULLIVAN, William C. Impact of views to school landscapes on recovery from stress and mental fatigue. Landscape and urban planning, v. 148, p. 149-158, 2016.

LIAO, Jiaqiang et al. Residential exposure to green space and early childhood neurodevelopment. Environment international, v. 128, p. 70-76, 2019.

LINDBERG, Casey M. et al. Effects of office workstation type on physical activity and stress. Occupational and environmental medicine, v. 75, n. 10, p. 689-695, 2018.

LIU, Qunyue et al. The relationship between self-rated naturalness of university green space and students' restoration and health. Urban Forestry \& Urban Greening, v. 34, p. 259-268, 2018.

MACNAUGHTON, Piers et al. Impact of particulate matter exposure and surrounding "greenness" on chronic absenteeism in Massachusetts public schools. International journal of environmental research and public health, v. 14, n. 2, p. 207, 2017.

MAGALHÃES, M. T. Q. Introdução à Mobilidade Urbana in REABILITA - Curso de pós-graduação lato sensu em Reabilitação Ambiental Sustentável Arquitetônica e Urbanística. Faculdade de Arquitetura e Urbanismo, Universidade de Brasília. Brasília, 2019.

MARKEVYCH, lana et al. Access to urban green spaces and behavioural problems in children: Results from the GINIplus and LISAplus studies. Environment international, v. 71, p. 29-35, 2014.

MATSUOKA, Rodney $\mathrm{H}$. Student performance and high school landscapes: Examining the links. Landscape and urban planning, v. 97, n. 4, p. 273-282, 2010.

NORWOOD, Michael Francis et al. A narrative and systematic review of the behavioural, cognitive and emotional effects of passive nature exposure on young people: Evidence for prescribing change. Landscape and Urban Planning, v. 189, p. 71-79, 2019. 
PEREIRA, Mauricio Gomes; GALVÃO, Taís Freire. Extração, avaliação da qualidade e síntese dos dados para revisão sistemática. Epidemiologia e Serviços de Saúde, v. 23, n. 3, p. 577-578, 2014.

PEREIRA, Mauricio Gomes; GALVÃO, Taís Freire. Heterogeneidade e viés de publicação em revisões sistemáticas. Epidemiologia e Serviços de Saúde, v. 23, p. 775-778, 2014.

PUHAKKA, Riikka et al. Greening of daycare yards with biodiverse materials affords well-being, play and environmental relationships. International journal of environmental research and public health, v. 16, n. 16, p. 2948, 2019.

RIBEIRO, R. J. da C. Análise Espacial em Apoio à Reabilitação e ao Planejamento Urbano in REABILITA - Curso de pós-graduação lato sensu em Reabilitação Ambiental Sustentável Arquitetônica e Urbanística. Faculdade de Arquitetura e Urbanismo, Universidade de Brasília. Brasília, 2019.

SIVARAJAH, Sivajanani; SMITH, Sandy M.; THOMAS, Sean C. Tree cover and species composition effects on academic performance of primary school students. PLoS One, v. 13, n. 2, p. e0193254, 2018.

SMITH, Richard; BRADLEY, Graham. The influence of thermal conditions on teachers' work and student performance. Journal of Educational Administration, 1994.

SOUZA, Graziele Peixoto; ORELLANA, Vivian dos Santos Queiroz; LEIVAS, Pedro Henrique Soares. IMPACTO DO BULLYING NA PERFOMANCE ESCOLAR. 2017.

STAMEN, T. Graffiti deterrent proposed by horticulturalist [Press release]. Riverside: University of California, Riverside, 1993.

TALLIS, Heather et al. Are California elementary school test scores more strongly associated with urban trees than poverty?. Frontiers in psychology, v. 9, p. 2074, 2018.

ULRICH, Roger S. et al. Stress recovery during exposure to natural and urban environments. Journal of environmental psychology, v. 11, n. 3, p. 201-230, 1991.

VAN DEN BERG, Agnes E. et al. Green walls for a restorative classroom environment: a controlled evaluation study. Environment and Behavior, v. 49, n. 7, p. 791-813, 2017.

WALLNER, Peter et al. Reloading pupils' batteries: Impact of green spaces on cognition and wellbeing. International journal of environmental research and public health, v. 15, n. 6, p. 1205, 2018.

WESTMAN, Jessica et al. Children's affective experience of every-day travel. Journal of transport geography, v. 29, p. 95-102, 2013.

WU, Chih-Da et al. Linking student performance in Massachusetts elementary schools with the "greenness" of school surroundings using remote sensing. PloS one, v. 9, n. 10, p. e108548, 2014.

\section{Gabriela Teixeira da Costa}

Graduada em Arquitetura e Urbanismo pelo Centro Universitário de Brasília (2018); especialista em Reabilitação Ambiental Sustentável Arquitetônica e Urbanística pela Universidade de Brasília (2020) com defesa de artigo no $2^{\circ}$ Simpósio Reabilita; pesquisadora na linha de Qualidade Verde (2014- 
2015) e congressista no $9^{\circ}$ Congresso Ibero-Americano de Parques e Jardins Públicos (2015) e no XIII Congresso de Ensino, Pesquisa e Extensão do UniCEUB (2015).

Contribuição de coautoria: Fundamentação teórico-conceitual e problematização; pesquisa de dados e análise estatística; elaboração de figuras e tabelas; elaboração e redação do texto; seleção das referências bibliográficas.

\section{Abner Luis Calixter}

Doutor em Desenvolvimento Sustentável pela Universidade de Brasília (CDS - UnB); Mestre em Desenvolvimento Internacional Sustentável pela The Heller School for Social Policy and Management - Brandeis University (2014).

Contribuição de coautoria: Fundamentação teórico-conceitual e problematização; revisão do texto.

Como citar: COSTA, Gabriela Teixeira da, CALIXTER, Abner Luis. Uma revisão sistemática sobre a relação entre a presença de vegetação e o desempenho acadêmico. Revista Paranoá. n.30. Edição Temática: Olhares da Reabilitação Sustentável 3, 2021. DOI 10.18830/issn.1679-0944.n30.2021.17

Editores responsáveis: Caio Frederico e Silva e Daniel Richard Sant'anna 